\title{
Metabolic Engineering Design Strategies for Increasing Acetyl-CoA Flux
}

\author{
Jason T. Ku ${ }^{1}$, Arvin Y. Chen ${ }^{1}$ and Ethan I. Lan ${ }^{2, *} \mathbb{C}$ \\ 1 Institute of Molecular Medicine and Bioengineering, National Chiao Tung University, Hsinchu City 300, \\ Taiwan; noeidting@gmail.com (J.T.K.); sssh10136@gmail.com (A.Y.C.) \\ 2 Department of Biological Science and Technology, National Chiao Tung University, Hsinchu City 300, Taiwan \\ * Correspondence: ethanilan@nctu.edu.tw
}

Received: 7 April 2020; Accepted: 21 April 2020; Published: 23 April 2020

\begin{abstract}
Acetyl-CoA is a key metabolite precursor for the biosynthesis of lipids, polyketides, isoprenoids, amino acids, and numerous other bioproducts which are used in various industries. Metabolic engineering efforts aim to increase carbon flux towards acetyl-CoA in order to achieve higher productivities of its downstream products. In this review, we summarize the strategies that have been implemented for increasing acetyl-CoA flux and concentration, and discuss their effects. Furthermore, recent works have developed synthetic acetyl-CoA biosynthesis routes that achieve higher stoichiometric yield of acetyl-CoA from glycolytic substrates.
\end{abstract}

Keywords: acetyl-CoA; metabolic bypass; pyruvate dehydrogenase; coenzyme A

\section{Introduction}

The rapid development of genetic and genomic tools allowed discoveries of the genes and enzymes associated with the production of industrially important chemicals. Methods and principles of metabolic engineering have then enabled the modification and transfer of the pathways that associate with these genes to almost any organism of choice to produce chemicals for industrial purposes. As these production pathways are optimized through both enzyme selection and engineering, the production is often limited by the availability of essential central metabolites. These essential metabolites are naturally produced from pathways optimized for cellular growth rather than for chemical production. As such, metabolic rewiring designs are necessary for increasing flux towards these essential metabolites.

Acetyl-Coenzyme A (acetyl-CoA) is a key two-carbon, ignoring the CoA moiety which only serves as an acyl-carrier, metabolite precursor for the production of lipids, polyketides, isoprenoids, amino acids, and numerous other bioproducts used in biochemical, biofuel, and pharmaceutical industries. At the same time, acetyl-CoA is also involved in numerous essential central metabolic pathways such as the TCA cycle, fatty acid biosynthesis, and amino acid biosynthesis. Pyruvate dehydrogenase (Pdh), the primary enzyme responsible for acetyl-CoA biosynthesis, is allosterically regulated with pyruvate [1] as an activator and acetyl-CoA [2] and reduced nicotinamide adenine dinucleotide (NADH) [3] as inhibitors. Therefore, intracellular flux and concentration of acetyl-CoA are highly regulated [4-8] to avoid potential metabolic burdens. Using the growth of Escherichia coli with glucose as an example, while flux towards acetyl-CoA has been measured to be about the same glucose uptake $[9,10]$, this flux represents only about half of total glucose intake flux because of the stoichiometric ratio of glucose to acetyl-CoA is 1:2. In addition, its intracellular concentration is kept at relatively low levels. For example, intracellular acetyl-CoA in E. coli was reported with a concentration of $0.05-1.5 \mathrm{nmol} / \mathrm{mg}$ cell dry weight (CDW), corresponding to 20-600 $\mu \mathrm{M}$ [11]. This situation makes it difficult for the production pathways utilizing enzymes with high $\mathrm{Km}$ for acetyl-CoA. The acetyl-CoA concentration increases with the cell growth followed by gradually decreasing when reaching stationary 
phase [11]. In addition, acetyl-CoA concentration varies according to salt stress [12], temperature [12], $\mathrm{pH}$ [12], and oxygenic level [13]. Carbon source also affects intracellular acetyl-CoA concentration as it has been measured to be $0.82,0.62$, and $0.37 \mathrm{nmol} / \mathrm{mg} \mathrm{CDW}$, for growth on glucose, glycerol, and succinate, respectively [12]. Therefore, metabolic strategies for manipulating acetyl-CoA flux and concentration is highly desirable to deal with different cultivation conditions.

To overcome the regulation of native acetyl-CoA biosynthesis, numerous strategies have been applied. This review summarizes the current approaches to increasing acetyl-CoA fluxes (Figure 1) from pyruvate and, in some cases, acetyl-CoA concentration as well. These approaches include overexpression of pyruvate dehydrogenase, increase of pyruvate supply, assimilation of acetate, inhibition of non-essential acetyl-CoA consumption, increase of CoA supply, and the construction of pyruvate dehydrogenase bypass. In addition, this review also discusses the recent development of novel metabolic pathways that lead to increased stoichiometric yield of acetyl-CoA from pyruvate through carbon conservation or additional carbon fixation. Together, the strategies presented in this work serves as a guide to metabolic engineering projects requiring acetyl-CoA as the metabolic precursor.

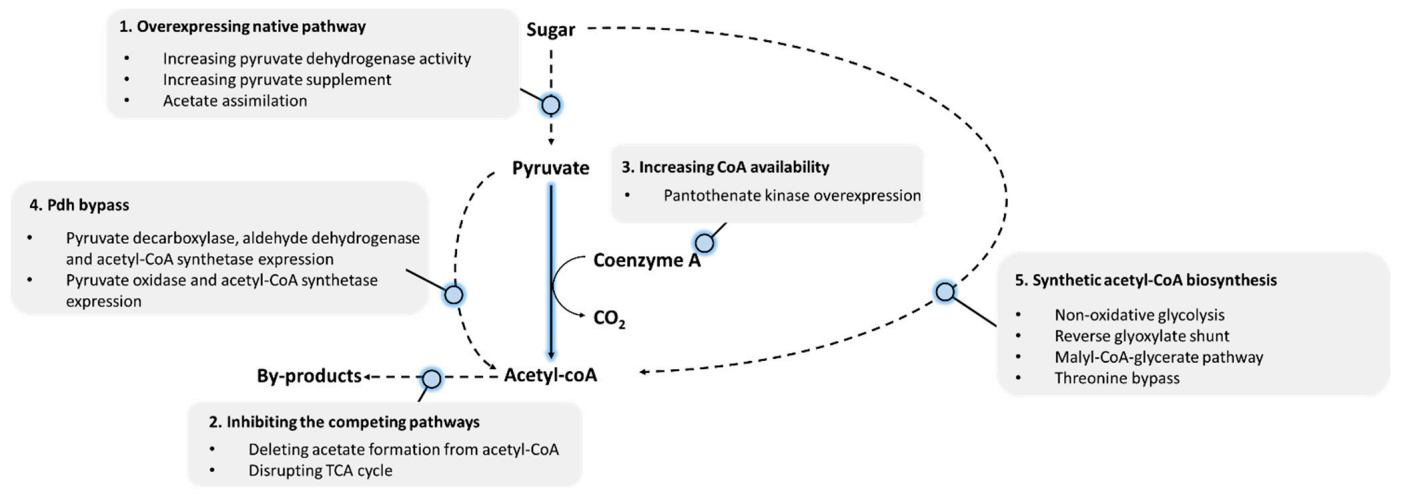

Figure 1. Summary of strategies for increasing acetyl-CoA flux and concentration in Escherichia coli. As acetyl-CoA is primarily synthesized from pyruvate, increase carbon flux toward pyruvate is an obvious strategy. Deletion of genes that are responsible for acetyl-CoA consumption is another commonly used strategy. Additionally, increase in CoA availability was demonstrated to functionally increase intracellular acetyl-CoA concentration. Since acetyl-CoA is primarily synthesized from pyruvate with an inevitable carbon loss, several pyruvate dehydrogenase bypasses were demonstrated to synthesize acetyl-CoA over theoretical yield. The bullet points listed in the gray area show the detail metabolic engineering method to meet each strategy. Dashed arrows indicate multi-step reactions.

\section{Overexpressing Native Pathways}

Acetyl-CoA is primarily synthesized from pyruvate through pyruvate dehydrogenase (Pdh) aerobically with $\mathrm{CO}_{2}$ and NADH formation [14]. On the other hand, pyruvate formate lyase (Pfl) serves as the major enzyme for acetyl-CoA formation anaerobically with formate as byproducts in bacterial hosts such as E. coli [15]. Since pyruvate is the direct precursor for acetyl-CoA synthesis, the most straightforward strategy for increasing acetyl-CoA flux and concentration is to increase the activity of Pdh or Pfl. Alternatively, increasing carbon flux toward pyruvate also drives formation of acetyl-CoA.

\subsection{Increasing Pyruvate Dehydrogenase Activity}

Pyruvate dehydrogenase complex is composed of three subunits, AceE, AceF, and Lpd (Figure 2). Although overexpression of Pdh complex has been thought to be difficult, its overexpression for increasing flux to acetyl-CoA has been applied to isoamyl acetate production in E. coli, which is a valuable ester that can be biosynthesized from the condensation of isoamyl alcohol and acetyl-CoA [16]. This study showed a 1.45-fold increase of the isoamyl acetate produced between Pdh overexpression 
strain and the parent strain, indicating the successful expression of Pdh. In a different study, the concentration of intracellular acetyl-CoA was measured with a 2-fold increase when Pdh was overexpressed [17]. In addition to Pdh overexpression, fine tuning its expression level through different copy number plasmids showed significant improvements in fatty acids production [18]. Pdh overexpression has also been achieved in model cyanobacterium Synechococcus elongatus PCC7942 with results of a 2-fold increase in acetyl-CoA concentration [19]. Contrary to the conventional notion that Pdh is difficult to overexpress, these studies have shown the positive effect of manipulating Pdh expression on intracellular acetyl-CoA flux and concentration.

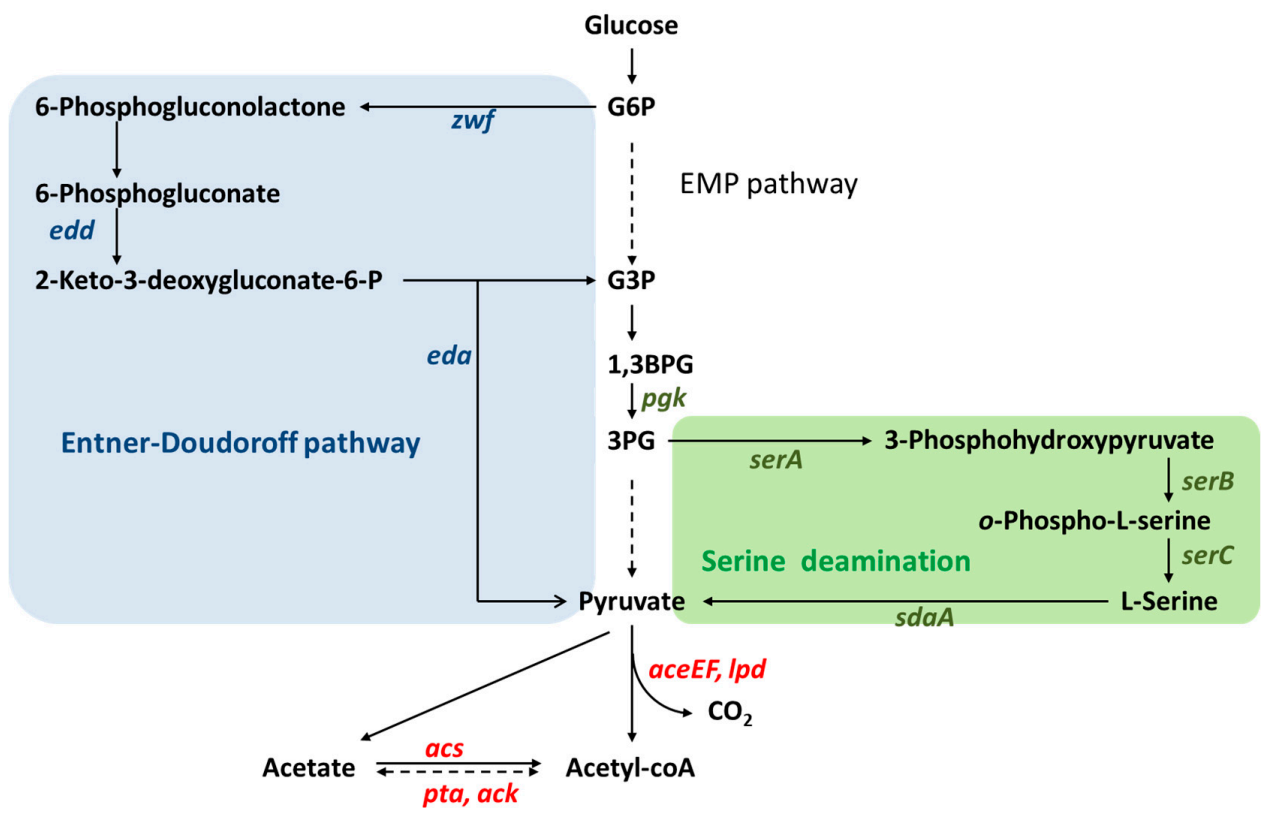

Figure 2. Pathways used to channel more carbon flux toward acetyl-CoA. Entner-Doudoroff pathway (ED pathway; blue shadowed area) is able to convert G6P into G3P and pyruvate independent from the conventional EMP pathway. Serine deamination (SD pathway; green shadowed area) on the other hand channeling pyruvate synthesis from the deamination of serine, which comes from the EMP pathway intermediate, 3PG. Overexpression of glycolysis, ED pathway, and SD pathway enhances pyruvate synthesis, which was expected to increase acetyl-CoA concentration since pyruvate is the precursor of acetyl-CoA. aceEF and lpd encode for pyruvate dehydrogenase, which is the primary enzyme responsible for acetyl-CoA synthesis. The italic labels represent the genes overexpressed for increasing carbon flux from sugar to acetyl-CoA. Dashed arrows indicate multi-step reactions. Abbreviations: $z w f$, glucose-6-phosphate dehydrogenase; $e d d, 6$-phosphogluconate

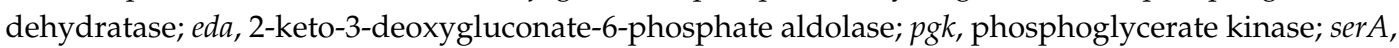
phosphoglycerate dehydrogenase; ser $B$, phosphoserine phosphatase; serC, phosphoserine; sdaA, L-serine deaminase; aminotransferase; $a c e E F$, pyruvate dehydrogenase; lpd, lipoamide dehydrogenase (E3 subunit); acs, acetyl-CoA synthetase; $p t a$, phosphate acetyltransferase; ack, acetyl-CoA kinase; G6P, glucose-6-phosphate; G3P, glyceraldehyde 3-phosphate; 1,3BPG, 1,3-bisphosphoglycerate; 3PG, 3-phosphoglycerate.

In addition to genetic regulation, Pdh is competitively inhibited by NADH [20], which prohibits high activity under anaerobic condition even with overexpression. Therefore, Kim et al. constructed a Pdh mutant that is less sensitive to inhibition by NADH [21]. The NADH insensitive Pdh mutant was achieved by introducing a E354K mutation on the E3 subunit Lpd. A later study reported a 5-fold increase in carbon flux through Pdh using this NADH insensitive mutant under anaerobic condition when compared to wild-type [22]. Expression of this mutant Pdh has also aided the production of butanol by 1.6-fold [23]. Similarly, expression of a mutant Pdh homologue from Klebsiella pneumonia led to a 2-fold increase in 1,4-butanediol production under anaerobic conditions [24]. Altogether, 
these results showed that overexpression of Pdh increases flux toward acetyl-CoA, leading to higher production of acetyl-CoA derived compounds. The oxygen insensitive Pdh mutant further provides a promising tool for increasing acetyl-CoA anaerobically.

\subsection{Increasing Pyruvate Flux Drives Downstream Acetyl-CoA Formation}

Increasing carbon flux through glycolysis to pyruvate directly drives the downstream acetyl-CoA formation. To do so, enzymes of glycolysis are targets for genetic overexpression. $\mathrm{Xu}$ et al. [17] used OptForce, a Flux balance analysis procedure that directly uses the available flux measurements to predict necessary genetic manipulations for compound overproduction [25], and identified phosphoglycerate kinase (Pgk) and glyceraldehyde-3-phosphate dehydrogenase (GapA) as two glycolytic enzymes targets for overexpression to achieve increased flux towards pyruvate produced through glycolysis. Their data showed a near 30\% increase in intracellular acetyl-CoA concentration upon overexpression of Pgk, leading to a near doubled flux towards their downstream product naringenin production [17].

In addition to glycolysis, typically referring to the Embden-Meyerhof-Parnas (EMP) pathway, other variants of glycolysis are also overexpression targets. For example, Zhang et al. [26] proposed a strategy of engineering the serine-deamination (SD) pathway and the Entner-Doudoroff (ED) pathway (Figure 2). Overexpression of $\operatorname{ser} A B C$ and $s d a A$, which enhances serine synthesis and serine deamination, improved pyruvate flux, leading to slight improvement on intracellular acetyl-CoA concentration by $10 \%$ [26]. Subsequently, a significant improvement on intracellular acetyl-CoA concentration was achieved by replacing the native promoter of the edd-eda operon, encoding for the ED pathway, with a constitutive promoter $\mathrm{P}_{\mathrm{J} 23119}$ and the native promoter of $z w f$ with another constitutive promoter $\mathrm{P}_{\mathrm{Trc}-162}$. Their resulting acetyl-CoA concentration therefore increased by 3-fold compared to the wild-type strain. Together with replacing native promoter of Pdh, their approach supported a relatively high flux production of poly-3-hydroxybutyrate (PHB), achieving a titer of $5.5 \mathrm{~g} / \mathrm{L}$ [26]. Together, these studies showed the effect that enhancing glycolytic flux towards pyruvate has on increasing acetyl-CoA concentration and resulting flux of desired downstream products.

\subsection{Acetate Assimilation into Acetyl-CoA}

Acetate is a secreted metabolite under both aerobic [27] and anaerobic conditions [28] and represent a major acetyl-CoA flux loss. In model organisms such as E. coli, it is synthesized from either pyruvate through pyruvate oxidase PoxB or acetyl-CoA through phosphate acetyltransferase Pta and acetyl-CoA kinase Ack (Figure 2). To address this loss of acetyl-CoA flux, acetyl-CoA synthetase Acs, catalyzing ATP dependent CoA-acylation of acetate to acetyl-CoA, overexpression was proposed to assimilate the secreted acetate back to acetyl-CoA (Figure 2) [29]. Lin et al. [29] showed the overexpression of native acs in E. coli decreased the secreted acetate from $11 \mathrm{mM}$ to a negligible level, indicating the efficient re-assimilation of acetate back to acetyl-CoA. Another study on fatty acid synthesis further showed that the intracellular acetyl-CoA concentration increased more than 3 -fold, reaching $3.5 \mathrm{nmol} / \mathrm{mg} \mathrm{CDW}$, with acs overexpression when compared to the wild-type strain [30]. As an alternative, phosphate acetyltransferase (encoded by $p t a$ ) and acetyl-CoA kinase (encoded by ack) were also used to assimilate acetate to acetyl-CoA [31,32] (Figure 2). By expressing the pta-ack operon, the $\mathrm{N}$-acetylglutamate production was increased by 2-fold [31]. These studies show that both the expression of Acs or Pta and Ack are viable methods to re-assimilate acetate produced. In addition to assimilating secreted acetate, supplementation of acetate into culture medium makes acs expression more effective on increasing intracellular acetyl-CoA [30,33].

\section{Inhibition of Competing Pathways}

Inhibition of competing pathways is a conventional metabolic engineering design principle. In attempts to increase acetyl-CoA flux, it is also a core design strategy used. However, pathways for the biosynthesis of essential metabolites such as fatty acids and amino acids using acetyl-CoA cannot be knocked out while maintaining suitable cellular growth rate. Although the rapid development of 
genetic tools such as sRNA [34] and CRISPRi [35] may allow transient and controlled partial inhibition, precise control is still challenging. As a result, most studies focus on inhibiting non-essential, but obvious and with large flux, pathways.

\subsection{Deletion of Phosphate Acetyltransferase and Acetyl-CoA Kinase to Reduce Acetate Production}

To block the acetate formation from acetyl-CoA, ackA-pta was the most frequently disrupted operon (Figure 3). Vadali et al. showed that the deletion of ackA-pta operon increased intracellular acetyl-CoA concentration by $16 \%$ with a residual acetate secretion of $4.5 \%$ compared to that of parent strain under anaerobic condition [36]. In conjunction with expression of an acetyl alcohol acetyltransferase (ATF2) and the supplementation of isoamyl alcohol, this strategy effectively increased isoamyl acetate, requiring acetyl-CoA as a direct precursor, production by 4.8-fold compared to the parent strain [36].

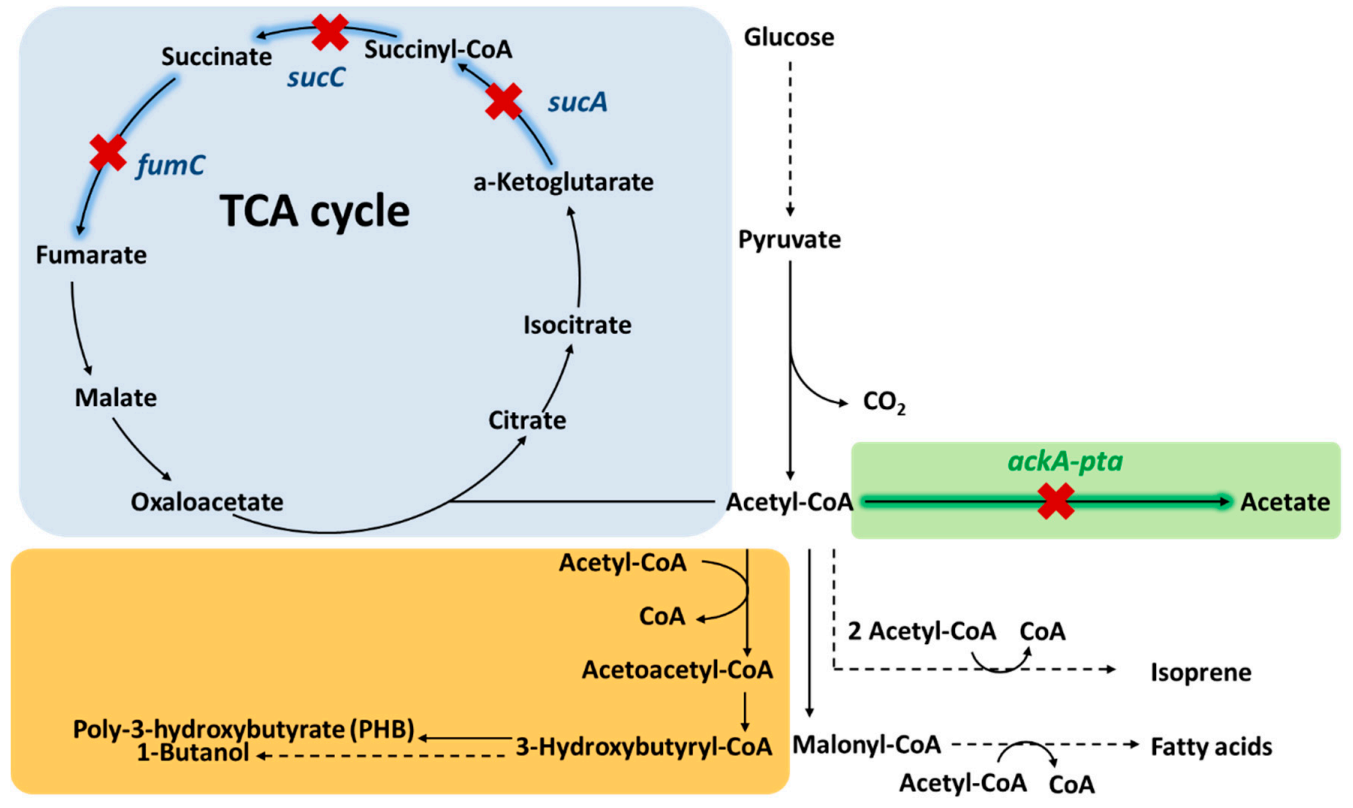

Figure 3. Genes inhibited to decrease acetyl-CoA consumption. Since acetate is a byproduct synthesized by $E$. coli under both aerobic and anaerobic condition, the acetate formation genes, ack $A$ and $p t a$, were frequently deleted to avoid the consumption of acetyl-CoA to acetate. ack and pta encode the enzyme of acetyl-CoA kinase and phosphate acetyltransferase, respectively. In addition, acetyl-CoA is consumed significantly by TCA cycle aerobically. Therefore, the deletion of $s u c A$, encoding for $\alpha$-ketoglutarate dehydrogenase, sucC, encoding for succinyl-CoA synthetase and fum $C$, encoding for fumarase, were also used for increasing acetyl-CoA concentration. The orange shadowed area represents the CoA-dependent pathway for 1-butanol and poly-3-hydroxybutyrate (PHB) synthesis, whose production improved by applying the deletion of acetyl-CoA consuming pathways. Dashed arrows indicate multi-step reactions.

In addition to pathways using acetyl-CoA as direct precursor to the desired product such as isoamyl acetate, other products requiring acetyl-CoA as a further upstream metabolite also benefit from ackA-pta operon knockout. One such pathway is the CoA-dependent chain extension pathway (Figure 3). Since both poly-hydroxybutyrate (PHB) and 1-butanol are both synthesized from two molecules of acetyl-CoA via CoA-dependent carbon chain extension (Figure 3), acetyl-CoA availability is believed to be an important parameter for high PHB [37] or 1-butanol synthesis [38]. Although the exact acetyl-CoA concentration and flux were not measured in the study of PHB biosynthesis, deletion of ack-pta increased the PHB production yield by $48 \%$ with the decreased of acetate formation [39]. 1-butanol production, on the other hand, was reported a significant improvement on titer by 10-fold with pta deletion [40]. A detailed metabolomics analysis was performed to the 1-butnaol production [41], showing that pta deletion increased intracellular acetyl-CoA concentration by 2-fold. In addition, this 
same study also measured the concentrations of other CoA intermediates in the CoA-dependent butanol synthesis pathway. Their results revealed that the CoA regeneration was inefficient enough due to the low activity of butyryl-CoA reductase, which probably limited the acetyl-CoA flux. After addressing the CoA recycling issue by expressing a higher activity reductase, the resulting strain showed a further 2-fold increase in intracellular acetyl-CoA concentration along with a 2-fold improvement in butanol production compared to the strain using original butyryl-CoA reductase [41]. These studies showed the effectiveness of $p t a$-ack knockout for streamlining carbon flux to acetyl-CoA and its downstream products. Furthermore, the metabolomics study on butanol production also suggested the importance of CoA recycling in order to keep its availability for acetyl-CoA turnover from pyruvate, leading to a higher acetyl-CoA flux.

Deletion of acetate formation was also applied to fatty acid [42] and isoprene production [43] (Figure 3). Since fatty acid biosynthesis requires acetyl-CoA and malonyl-CoA, which is also derived from acetyl-CoA, as precursors, deletion of pta itself increased total fatty acid synthesis titer by 1.5-fold [44] (Figure 3). In the case of isoprene production, three acetyl-CoA molecules are required using the mevalonate pathway. Kim et al. [43] showed initial demonstration of isoprene production using E. coli resulted in $7.4 \mathrm{~g} / \mathrm{L}$ of acetate produced as by-product. Upon deletion of the pta-ack operon, acetate formation was reduced to $1.4 \mathrm{~g} / \mathrm{L}$ while increasing isoprene production by about 2-fold [43]. A similar strategy of deleting phosphate acetyltransferase has been also applied to other chemical productions, such as acetaldehyde [45], itaconate [46], poly-3-hydroxybutyrate (PHB) $[39,47,48]$, butyraldehyde [49], acetone [50], and butanone [50] biosynthesis. This approach is one of the most well-demonstrated methods for enhancing acetyl-CoA supply.

\subsection{Disrupting TCA Cycle}

The TCA cycle represents a large acetyl-CoA drain especially during aerobic metabolism. It can be disrupted by inhibiting enzymes downstream of $\alpha$-ketoglutarate, particularly $\alpha$-ketoglutarate dehydrogenase. Inhibition of the $\alpha$-ketoglutarate dehydrogenase was achieved through deletion of sucA gene which codes for the E1 subunit. This strategy was used to improve the yield of mevalonate production [51]. In the same $\mathrm{Xu}$ et al. study [17] mentioned previously in Section 2.2 that used Optforce [25] to optimize acetyl-CoA flux, succinyl-CoA synthetase and fumarase were identified as two targets needed to be knocked down. Through deletion of sucC and fumC, coding for succinyl-CoA synthetase and fumarase, respectively, acetyl-CoA concentration increased by more than 2-fold compared to the strain without these deletions. Together with overexpression of Pdh, increasing pyruvate flux, and acetyl-CoA carboxylase expression, their product naringenin titer improved from 85.5 to $474 \mathrm{mg} / \mathrm{L}$, demonstrating the beneficial effect of increased acetyl-CoA availability on polyketide synthesis. Genes coding for TCA cycle enzymes responsible for the synthesis of $\alpha$-ketoglutarate are generally not deleted due to inability to grow under defined media by the resulting stain. Reduced carbon flux to $\alpha$-ketoglutarate also impaired cellular growth [52]. Nonetheless, citrate synthase knockout has been shown to increase acetyl-CoA availability for citramalate synthesis, which requires acetyl-CoA as the direct precursor [53]. The downside such approach is the required supplement of glutamate in culture medium. Together, these studies showed the versatility of deleting the competing pathway to increase acetyl-CoA concentration and flux.

\section{Increasing CoA Availability}

Concentration of intracellular CoA is the upper limit to that of acetyl-CoA. Natural intracellular acetyl-CoA concentration may be insufficient to drive high flux conversion to its downstream products in some cases due to higher $\mathrm{Km}$ of the enzymes involved. For example, the $\mathrm{Km}$ of CoA-acylating aldehyde dehydrogenase used in ethanol production from Salmonella enterica is $342 \mu \mathrm{M}$ [54], which is around or higher than the natural acetyl-CoA concentration in model hosts such as E. coli. To override the native regulation [55] that controls intracellular CoA concentration, Vadali et al. [56] proposed to increase intracellular acetyl-CoA and CoA concentration by overexpressing the native panK gene to 
avoid the regulation in E. coli. Pantothenate kinase (PanK; also named as CoaA) is the most regulated step in CoA synthesis [57,58] and is sensitively feedback inhibited by CoA pool [59,60] (Figure 4). The acetyl-CoA concentration in the panK overexpression strain increased by 3-fold compared to the control strain [56]. This strategy was further applied to isoamyl acetate production [61]. By combining the competing pathway knockout with increasing CoA availability, isoamyl alcohol production was increased by 2.27-fold compared to the control strain without any acetyl-CoA concentration elevating strategy. Notably, the intracellular CoA and acetyl-CoA concentration increased by 3.17-fold and 2.27-fold in the engineered strain, respectively.

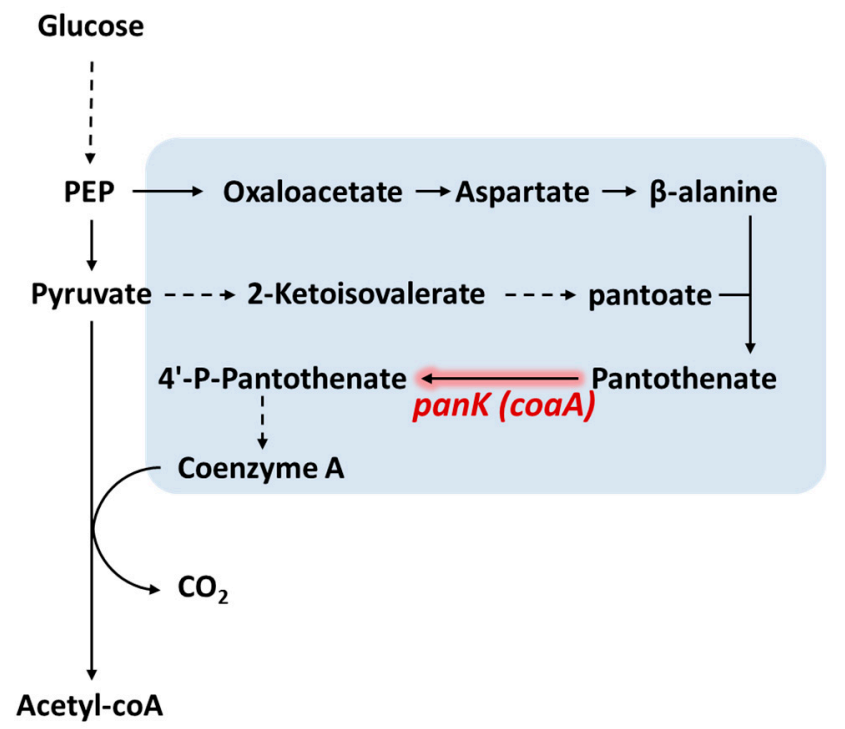

Figure 4. Scheme of coenzyme A synthesis. The coenzyme A synthesis pathway is shadowed in blue. panK (also named as coaA) was the committed step for coenzyme synthesis, which is proposed to be expressed to increase both coenzyme A and acetyl-CoA concentration. Dashed arrows indicate multi-step reactions. Abbreviation: PEP, phosphoenolpyruvate.

Expressing pantothenate kinase to increase intracellular acetyl-CoA for improving bioproduction was also applied to succinate biosynthesis [62]. Since succinate is an intermediate of the TCA cycle, whose substrate is acetyl-CoA and oxaloacetate, increased acetyl-CoA concentration was expected to improve succinate production. Furthermore, PEP carboxylate (Ppc) and pyruvate carboxylase (Pyc), enzymes responsible for oxaloacetate synthesis and key to succinate production, were reported to require acetyl-CoA for activation $[63,64]$. Therefore, higher acetyl-CoA concentration aided in the activity of Ppc and Pyc. panK and ppc overexpression led to increased acetyl-CoA concentration from 0.24 to $8.05 \mu \mathrm{M}$ and accompanied by a $30 \%$ improvement in succinate production [62].

Recently, the CoA and acetyl-CoA contents in E. coli strain expressing pantothenate kinases from different organisms, including Staphylococcus aureus (Sa_coaA), Pseudomonas putida (Pp_coaA), and E. coli (Ec_coaA), were further investigated [65]. The results showed that the intracellular acetyl-CoA content can be efficiently enhanced by expressing any of the coaA genes. While the expression of $S a \_c o a A$ resulted in a similar amount of acetyl-CoA to the strain that expressed $E c \_c o a A$, the expression of $P p \_c o a A$ led to the highest amount of acetyl-CoA and total CoA content, achieving about 3-fold compared to the strain without pantothenate kinases overexpression under the same condition. Notably, acetyl-CoA occupied more than $70 \%$ of the total CoA content whether the pantothenate kinases were overexpressed or not, indicating the feasibility of increasing CoA availability to improve acetyl-CoA derived biochemical production. Although most of the studies expressed pantothenate kinase from E. coli to increase acetyl-CoA, this study showed the pantothenate kinase from P. putida may be a better candidate. 


\section{Construction of Pyruvate Dehydrogenase Bypass}

Although several studies have shown the positive effect of pyruvate dehydrogenase overexpression, Pdh is nonetheless regulated by a variety of allosteric effectors [3], which may be difficult to completely control. Therefore, as an alternative, a bypass pathway consisting of pyruvate decarboxylase, acetaldehyde dehydrogenase, and acetyl-CoA synthetase (Figure 5) was used to convert pyruvate to acetyl-CoA. This pathway was particularly useful for the metabolic engineering of yeasts in productions that require acetyl-CoA [66]. In model yeasts such as Saccharomyces cerevisiae, Pdh is located in mitochondria whereas most biosynthesis occurs in the cytosol. Therefore, through the construction of this Pdh-bypass, acetyl-CoA concentration was increased from around $0.36 \mathrm{nmol} / \mathrm{g} \mathrm{CDW}$ to more than $1.1 \mathrm{nmol} / \mathrm{g}$ CDW, representing a 3-fold improvement [67]. The expression of this bypass was shown to improve mevalonate production from 1.78 to $2.52 \mathrm{mM}$ [66]. A different Pdh bypass was constructed in E. coli through the expression of pyruvate oxidase PoxB and acetyl-CoA synthetase Acs. Using the Pdh bypass, acetyl-CoA is synthesized from acetate, which comes from the decarboxylative oxidation of pyruvate (Figure 5). This version of the Pdh bypass was shown to improve intracellular acetyl-CoA concentration by 2-fold [68], which led to an increase of isopropanol production.

\section{Glucose}

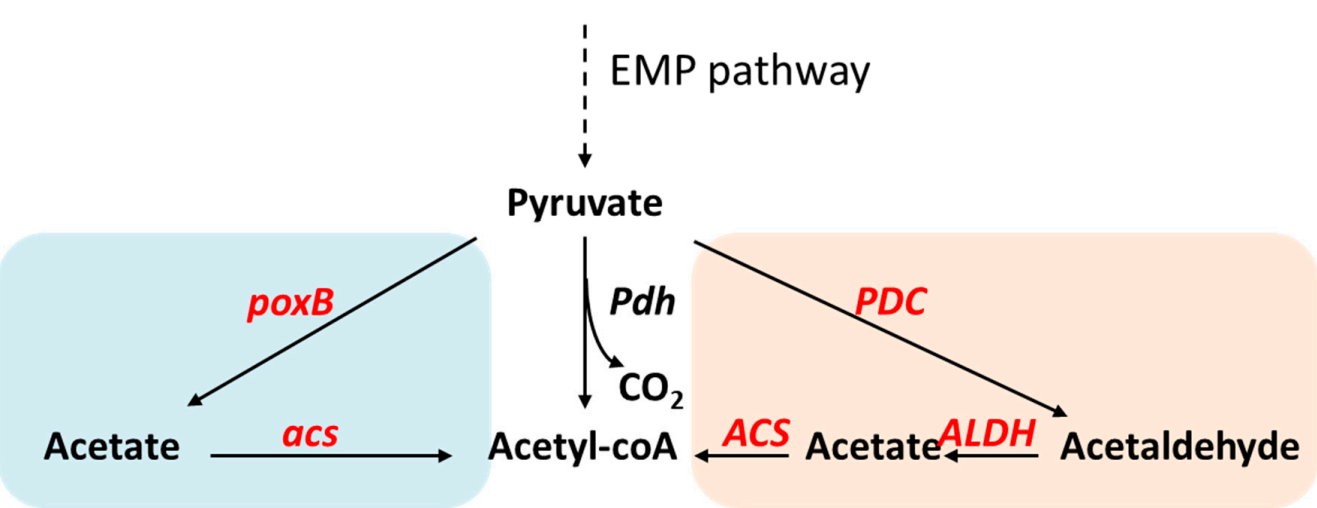

Figure 5. Scheme of pyruvate dehydrogenase (Pdh) bypass. Pdh bypass allows acetyl-CoA synthesis from pyruvate independent from Pdh. The pink area was naturally occuring in Saccharomyces cerevisiae, providing acetyl-CoA in cytosol. The blue shadowed area, on the other hand, was first used in E. coli. Both of the Pdh bypass versions were used to increase acetyl-CoA concentration for metabolic engineered bioproduction. Abbreviation: poxB, pyruvate oxidase; acs, acetyl-CoA synthetase; PDC, pyruvate decarboxylase; $A L D H$, aldehyde dehydrogenase.

Photoautotrophic hosts such as cyanobacteria usually do not possess obvious acetyl-CoA drains such as the pta-ack operon. As a result, pathways requiring large acetyl-CoA flux such as the CoA-dependent chain extension pathway for butanol and butyrate production is limited and requires alternative pathway engineering $[69,70]$. Nonetheless, Pdh bypass has recently been engineered into model cyanobacterium Synechococcus elongatus PCC 7942 and helped to increase the intracellular acetyl-CoA concentration from 17 to $138 \mu \mathrm{g} / \mathrm{g}$ CDW [71]. Together, Pdh bypass increases intracellular acetyl-CoA by serving as an alternative for acetyl-CoA synthesis from pyruvate with same carbon yield. However, depending on the pathway for acetyl-CoA derived compound synthesis, the ATP consumption during the activation of acetate to acetyl-CoA in Pdh bypass may lower the production yield.

\section{Synthetic Acetyl-CoA Biosynthesis}

Although various strategies described above successfully increased acetyl-CoA concentration or flux, conversion of pyruvate to acetyl-CoA is coupled to an inevitable loss of carbon. Due to the decarboxylation of pyruvate, the stoichiometric yield of acetyl-CoA from glucose is 2 mole per mole of 
glucose. To go beyond this stoichiometric yield, novel synthetic pathways (Figure 6) are constructed to conserve or fix additional carbon into acetyl-CoA.

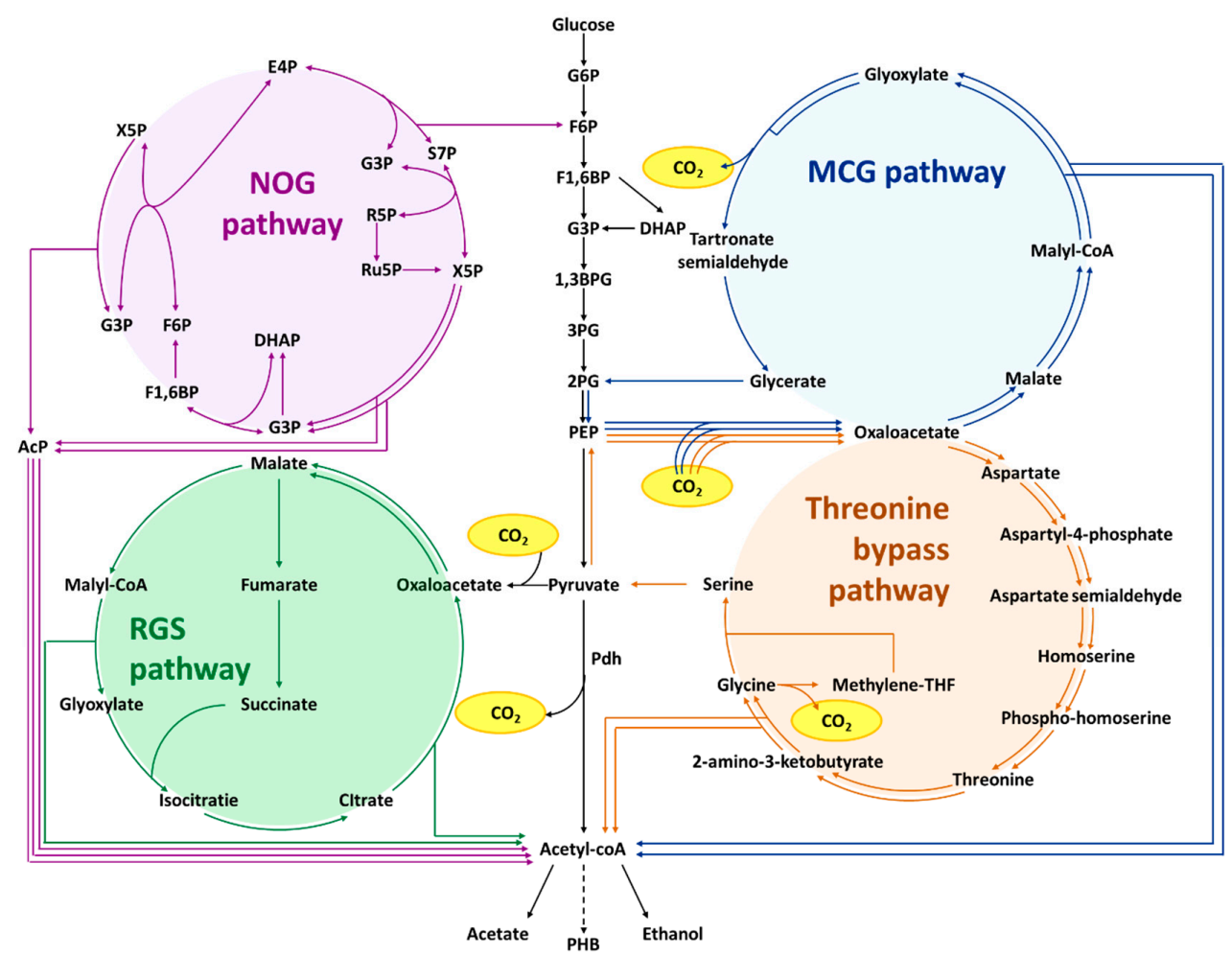

Figure 6. Synthetic Pdh bypass to increase the acetyl-CoA yield from sugar. The purple arrows indicate the non-oxidative glycolysis (NOG) pathway, which converts sugar phosphate to the acetyl-phosphate or further acetyl-CoA in a stoichiometry amount. The green arrows indicate the reverse glyoxylate shunt (rGS), leading to two acetyl-CoA from one pyruvate. The blue arrows indicate the malyl-CoA-glycerate (MCG) pathway, which net converts one phosphoenolpyruvate (PEP) to two acetyl-CoA. The orange arrows indicate the threonine bypass, which is able to convert one PEP into two acetyl-CoA. Redox equivalents and energy requirements of each reaction are not shown in this scheme. Abbreviations: G6P, glucose-6-phosphate; F6P, fructose-6-phosphate; F1,6P, fructose-1,6-bisphosphate; DHAP, dihydroxyacetone phosphate; G3P, glyceraldehyde 3-phosphate; 1,3BPG, 1,3-bisphosphoglycerate; 3PG, 3-phosphoglycerate; 2PG, 2-phosphoglycerate; PEP, phosphoenolpyruvate; X5P, xylulose-5-phosphate; E4P, erythrose-4-phosphate; S7P, sedoheptulose-7-phosphate; R5P, ribose-5-phosphate; Ru5P, ribulose-5-phosphate.

\subsection{Non-Oxidative Glycolysis (NOG)}

The non-oxidative glycolysis [72] is a synthetic pathway that completely conserves carbon when converting glucose to acetyl-CoA. It allows for the production of three acetyl-CoA molecules from a glucose. The key enzyme involved is a phosphoketolase which can cleave either fructose-6-phosphate (F6P) or xylulose-5-phosphate (X5P) into erythrose-4-phophate (E4P) or glyceraldehyde-3-phosphate (G3P), respectively, and acetyl-phosphate [73]. Represented in Figure 6 is the version of the non-oxidative glycolysis (NOG) pathway based on X5P cleavage. Acetyl-phosphate is then converted into acetyl-CoA through phosphate acetyltransferase Pta. Through sugar-phosphate rearrangement naturally used in both the pentose phosphate pathway or the Calvin cycle (Figure 6), a net reaction of one F6P to three acetyl-phosphate is possible. Furthermore, the phosphoketolase catalyzed reaction is generally irreversible and therefore provided a driving force for this pathway. Using this pathway, Bogorad et al. [72] showed a production of $3.6 \mathrm{~g} / \mathrm{L}$ acetate from xylose with a yield of 2.2 (mole/mole xylose), which was above the theoretical yield of 1.67 (mole/mole xylose) using native glycolysis. Notably, 
although the intracellular acetyl-CoA concentration was not quantified, the NOG strain was reported with an intracellular acetyl-phosphate concentration of $10 \mathrm{mM}$, which can be easily converted to acetyl-CoA. On the other hand, the strain without NOG pathway expression only has acetyl-phosphate concentration of below $1 \mathrm{mM}$, showing the efficient acetyl-phosphate generation by the NOG pathway. Recently, by combining rational design, genome editing, and evolution, the same group was able to implement this NOG pathway into E. coli for EMP glycolysis independent growth [74]. The resulting strain, containing 11 gene overexpressions, 10 gene deletions by design, and more than 50 genomic mutations (including three global regulators), was able to convert $83 \%$ carbon from glucose into acetate [74]. While complete carbon conservation implies no reducing cofactors can be produced, this pathway offers a great potential to significantly increase the yield of acetyl-CoA derived product with the addition of an external electron source such as hydrogen.

\subsection{Reverse Glyoxylate Shunt ( $r G S$ )}

In addition to carbon conservation pathway, a synthetic reversed glyoxylate shunt [75] was also engineered to convert one pyruvate molecule into two acetyl-CoA, thereby achieving carbon fixation (Figure 6). Pyruvate is first carboxylated into a four-carbon oxaloacetate, that is subsequently reduced and cleaved into two acetyl-CoA molecules. To most model prokaryotes, this pathway requires introduction of only two enzymes: malate thiokinase and malyl-CoA lyase. This pathway has been demonstrated through conditional auxotrophies of TCA intermediates. An oxaloacetate/aspartate auxotrophic E. coli was rescued by this pathway using malate and succinate [75], indicating the functional expression of the pathway. While this pathway shows promise for substantially increasing stoichiometric yield of glucose to acetyl-CoA to 1:4 with addition of an external electron source such as hydrogen due to two acetyl-CoA produced from one pyruvate, it is still in early stages of development and has yet to be characterized in more detail.

\subsection{Malyl-CoA-Glycerate Pathway (MCG Pathway)}

The Malyl-CoA glycerate (MCG) pathway [76] achieved a similar effect as that of the reverse glyoxylate shunt (rGS) pathway mentioned above. This synthetic pathway starts from carboxylating two phosphoenolpyruvate (PEP) to two oxaloacetate molecules. Subsequently, the two oxaloacetate is reduced and activated into malyl-CoA, similar to that of rGS. Malyl-CoA is cleaved into acetyl-CoA and glyoxylate. Here, two glyoxylates are then used to regenerate PEP through tartronate semialdehyde (Figure 6). The overall reaction using MCG pathway produces two molecule acetyl-CoA from a molecule PEP with three molecule NADH and two molecule ATP consumption. Similar to the rGS, using this pathway would increase the stoichiometric yield of glucose to acetyl-CoA from 1:2 to 1:4 with addition of external electron source such as hydrogen. This pathway is easier to construct than the rGS because it does not contain a bifurcation at the malate node that the rGS has. With the expression of MCG pathway, Yu et al. showed that E. coli was able to produce acetate and ethanol with yield of 2.9 (mole C2 compound/mole glucose), which is over the theoretical yield using the native acetyl-CoA synthesis pathway [76]. This functional demonstration of exceeding natural stoichiometric yield outperforms the rGS.

\subsection{Threonine Bypass}

Lin et al. [77] constructed a threonine bypass based on flux balance analysis (FBA) to increase the intracellular acetyl-CoA flux for Poly-hydroxybutyrate production (Figure 6). The net effect of this pathway is identical to the rGS and MCG pathways where one mole of PEP converts to two moles of acetyl-CoA. The pathway started from carboxylating phosphoenolpyruvate (PEP) into oxaloacetate followed by a threonine synthesis pathway. Then, the threonine is oxidized to 2-amino-3-ketobutyrate followed by the cleavage into acetyl-CoA and glycine. The glycine is then converted to serine via a THF mediated reaction. Finally, serine was deaminated into pyruvate, which can be used to regenerate PEP. In their work, Lin et al. [77] showed a 3-fold increase in intracellular acetyl-CoA concentration 
upon the expression of this threonine bypass, resulting in a Poly-hydroxybutyrate titer increase from 2.08 to $5.97 \mathrm{~g} / \mathrm{L}$.

Together with the above-mentioned rGS and MCG pathways, these three pathways are capable of producing two molecules of acetyl-CoA from one molecule of PEP or pyruvate. If supplemented with inorganic electron source such as hydrogen, the maximum stoichiometric yield from glucose becomes 1:4. While functional demonstration and applications of these pathways in producing acetyl-CoA based compounds are still in its early developmental stages, these pathways offer substantial promise. Currently, these pathways require additional modifications such as identification and increase the rate limiting step in order for them to be more widely applied. Furthermore, as with the development of the NOG pathway [72,74], optimized implementation of these pathways may require a combination of rational design, genome editing, and evolution, to truly enable high performance of acetyl-CoA derived compound productions.

\section{Conclusions}

Recent advances on metabolic engineering provides the production of wide variety of compounds. As an essential central metabolite, acetyl-CoA serves as the precursor to various chemicals while supporting cellular growth. In the past decades, significant efforts have focused on increasing flux and concentration of intracellular acetyl-CoA in order to support microbial chemical synthesis. Conventionally, overexpressing the native pathway for acetyl-CoA synthesis and deletion of competing pathways are the most commonly used strategies. As an alternative, providing CoA for efficient acetyl-CoA synthesis was also demonstrated to function on increasing acetyl-CoA flux.

Recently, advances in bioinformatics and metabolic engineering tools enables further bold design of synthetic pathways, such as the NOG pathway, rGS, MCG pathway, and threonine bypass, allowing over theoretical yield of acetyl-CoA synthesis from sugar. While these synthetic pathways have been demonstrated in their respective studies, their optimized integration into microbial cell factories still require additional work.

Acetyl-CoA flux and concentration remains a tricky challenge to metabolic engineers. As a central primary metabolite, its complex interaction with transcriptome and proteome has yet to be completely deciphered. For example, a recent study on threonine synthesis showed that acetyl-CoA concentration increased significantly by 2.1-fold with the expression of the PHB synthetic pathway [78]. Although the increased acetyl-CoA concentration can be explained by downregulation of pta-ack operon and upregulation of acs, its molecular basis remains unclear.

Although this review primarily discusses studies using E. coli as an example to show the strategies for increasing acetyl-CoA flux and concentrations, these strategies can also be applied to other organisms with appropriate modification. For example, eukaryotes, such as S. cerevisiae, synthesize acetyl-CoA in mitochondria without the ability of transporting to cytosol, Pdh bypass [66], or ATP citrate lyase mediated acetyl-CoA synthesis [79] hence was required to increase cytosol acetyl-CoA content. Pdh overexpression was used in S. serevisiae to increase acetyl-CoA concentration [80], however, required lipoic acid supplementation.

In conclusion, the effects of the approaches discussed in this review and summarized in Table 1 are convincing as these works either directly quantified intracellular acetyl-CoA concentration or showed a significant increase of their acetyl-CoA derived bioproducts (Table 2). 
Table 1. Strategies for increasing acetyl-CoA and acetyl-CoA based products.

\begin{tabular}{|c|c|c|c|c|}
\hline Approach & Strategy & Genetic Manipulations & Rational & Example \\
\hline \multirow{5}{*}{$\begin{array}{l}\text { Overexpressing } \\
\text { native pathways }\end{array}$} & $\begin{array}{l}\text { Increase pyruvate } \\
\text { dehydrogenase } \\
\text { activity }\end{array}$ & Overexpressing $a c e E F$, lpd & $\begin{array}{c}\text { Overexpression of pyruvate } \\
\text { dehydrogenase to increase activity }\end{array}$ & {$[16,17]$} \\
\hline & & Lpd * (E354K) & $\begin{array}{l}\text { Introducing the mutation in E3 subunit of } \\
\text { Pdh increased anaerobic activity due to } \\
\text { insensitive to NADH }\end{array}$ & {$[22,23]$} \\
\hline & $\begin{array}{l}\text { Increase pyruvate } \\
\text { supplement }\end{array}$ & $\triangle \operatorname{ser} C:: P_{t r c-162}:: p g k, \operatorname{ser} A B C$ & $\begin{array}{l}\text { Entner-Doudoroff pathway converts } \\
\text { glucose-6-phopshate to pyruvate using } \\
\text { the genes, } z w f \text {, edd, and } e d a\end{array}$ & [26] \\
\hline & & $\begin{array}{c}\mathrm{P}_{\text {sdaA }}:: \mathrm{P}_{\text {trc }} ; \mathrm{P}_{\text {edd-eda }}:: \mathrm{P}_{\mathrm{J} 23119} \\
\mathrm{P}_{z w f f:}: \mathrm{P}_{\text {trc }-162}\end{array}$ & $\begin{array}{l}\text { Pgk helps to provide } 3 \text { PG from 1,3BPG. } \\
\text { Then, the serine-deamination pathway } \\
\text { converts } 3 \text { PG into pyruvate using the } \\
\text { genes } \operatorname{ser} A B C \text { and } s d a A \text {. }\end{array}$ & [26] \\
\hline & Assimilate acetate & Overexpressing $a c s$ or $p t a-a c k$ & $\begin{array}{l}\text { Activating acetate into acetyl-CoA, } \\
\text { allowing the assimilation of naturally } \\
\text { secreted or supplemented acetate }\end{array}$ & [31-33] \\
\hline \multirow{4}{*}{$\begin{array}{l}\text { Inhibiting the } \\
\text { competing } \\
\text { pathway }\end{array}$} & $\begin{array}{l}\text { Deleting acetate } \\
\text { formation from } \\
\text { acetyl-CoA }\end{array}$ & $\Delta p t a$ & $\begin{array}{l}\text { Deletion of phospho acetyltransferase } \\
\text { blocks the consumption of acetyl-CoA } \\
\text { into acetate }\end{array}$ & {$[40,42,43]$} \\
\hline & $\begin{array}{l}\text { Disrupting TCA } \\
\text { cycle }\end{array}$ & $\triangle s u c A$ & $\begin{array}{l}\text { Deletion of } \alpha \text {-ketoglutarate } \\
\text { dehydrogenase }(s u c A) \text { disrupts the TCA } \\
\text { cycle but maintains glutamate synthesis }\end{array}$ & [51] \\
\hline & & $\triangle s c u C \triangle f u m C$ & $\begin{array}{c}\text { Deletion of succinyl-CoA synthetase } \\
(\text { sucC) and fumarase }(\text { fum } C) \text { disrupt the } \\
\text { TCA cycle }\end{array}$ & [17] \\
\hline & & $\triangle g l t A$ & $\begin{array}{l}\text { Deletion of citrate synthase to block the } \\
\text { first step of the TCA cycle }\end{array}$ & [53] \\
\hline $\begin{array}{l}\text { Enhancing CoA } \\
\text { availability }\end{array}$ & $\begin{array}{l}\text { Enhance CoA } \\
\text { synthesis }\end{array}$ & Overexpressing panK & $\begin{array}{l}\text { Pantothenate kinase serves as the limiting } \\
\text { step of CoA synthesis }\end{array}$ & {$[56,61]$} \\
\hline \multirow{2}{*}{ Pdh bypass } & Pdh bypass & $\begin{array}{c}\text { Overexpressing } P D C, A C D H, \\
\text { and } A C S\end{array}$ & $\begin{array}{l}\text { PDC, ACDH, and ACS allows the } \\
\text { conversion of pyruvate to acetyl-CoA via } \\
\text { acetaldehyde and acetate as intermediate }\end{array}$ & [66] \\
\hline & & Overexpressing poxB and $a c s$ & $\begin{array}{l}\text { poxB and acs allow the conversion of } \\
\text { pyruvate to acetyl-CoA via acetate as } \\
\text { intermediate }\end{array}$ & [68] \\
\hline \multirow{5}{*}{$\begin{array}{l}\text { Synthetic } \\
\text { acetyl-CoA } \\
\text { biosynthesis }\end{array}$} & $\begin{array}{l}\text { Non-oxidative } \\
\text { glycolysis }\end{array}$ & $\begin{array}{c}\Delta a d h E, \Delta l d h A, \Delta f r d B C, \Delta p f l B \\
P_{\text {LlacO1 }}: f b p, f x p k\end{array}$ & $\begin{array}{l}\text { Expression of fructose 1,6-bisphosphatase } \\
\text { and phosphoketolase, allowing the } \\
\text { conversion of glucose-phosphate to } \\
\text { stoichiometry amount acetyl-phosphate } \\
\text { or acetyl-CoA }\end{array}$ & [72] \\
\hline & $\begin{array}{l}\text { Non-oxidative } \\
\text { glycolysis }\end{array}$ & $\begin{array}{c}\text { Evolved strain with } 50 \\
\text { genomic mutation and } \\
\mathrm{P}_{\mathrm{LlacO} 1: x p k_{B A}}, g l f_{Z M}, g l k, \\
t k t 2_{M B}, t a l_{K P}, g l p X \\
\mathrm{P}_{\mathrm{LlacO} 1}: t k t 2_{M B}, t k t 1_{M B} \\
\end{array}$ & $\begin{array}{c}\text { Combining evolution, the NOG pathway } \\
\text { supports } E \text {. coli growth and nearly } \\
\text { complete carbon conservation from } \\
\text { glucose to acetyl-phosphate or } \\
\text { acetyl-CoA }\end{array}$ & [74] \\
\hline & $\begin{array}{l}\text { Reverse glyoxylate } \\
\text { shunt }\end{array}$ & $\begin{array}{c}\Delta \text { gltA } \Delta \text { mdh } \Delta \text { ppc } \Delta \text { citE } \\
\Delta \text { mqo } \Delta \text { aceB } \Delta \text { icd } \\
\mathrm{P}_{\text {LlacO1 }: \text { DctA, PLlacO1::AceA; }} \\
\text { P }_{\text {LlacO1 }}: \text { AcnA; } P_{\text {LlacO1: }}: \text { AclB, } \\
\text { AclA; } \mathrm{P}_{\text {LlacO1: }}: \text { SucCD-2, Mcl1 }\end{array}$ & $\begin{array}{c}\text { rGS provides a net conversion of C4 } \\
\text { compound such as malate into two } \\
\text { acetyl-CoA }\end{array}$ & [75] \\
\hline & $\begin{array}{l}\text { Malyl-CoA-glycerate } \\
\text { cycle }\end{array}$ & $\begin{array}{c}\Delta a c e B \Delta g l c B \Delta f r d B \Delta l d h A \\
\Delta p s t G \\
\mathrm{P}_{\text {LlacO1 }:: m t k B, m t k A(M . c), m c l} \\
\mathrm{P}_{\text {LlacO1 }:: g c l, h y i} \\
\mathrm{P}_{\text {LlacO1 }:: g a r K,}, m d h \\
\mathrm{P}_{\text {LlacO1 }:: p p c}\end{array}$ & $\begin{array}{l}\text { PEP carboxylase, malate dehydrogenase, } \\
\text { malate thiokinase, and malyl-CoA lyase } \\
\text { together with glyoxylate assimilation } \\
\text { pathway allows two acetyl-CoA from PEP }\end{array}$ & [76] \\
\hline & Threonine bypass & $\begin{array}{c}\mathrm{P}_{k b l-t d h}:: \mathrm{P}_{t r c}, \mathrm{P}_{\text {sdaA }}:: \mathrm{P}_{t r c}, \\
\text { thrA::thrA } \text { (C1034T), } \\
\mathrm{P}_{\text {thrABC }}:: \mathrm{P}_{\text {Trc-162 }}, \mathrm{P}_{\text {ppc }}:: \mathrm{P}_{\text {tac }}, \\
\mathrm{P}_{\text {glyA }}:: \mathrm{P}_{\text {Trc }-162}\end{array}$ & $\begin{array}{l}\text { Expression of threonine synthesis } \\
\text { pathway and threonine degradation } \\
\text { converts PEP to acetyl-CoA and glycine, } \\
\text { which is next converted to pyruvate. } \\
\text { Together, generating an extra acetyl-CoA. }\end{array}$ & [77] \\
\hline
\end{tabular}

${ }^{*}$ Mutant enzyme. 
Table 2. The effects of applying acetyl-CoA increasing strategy on biochemical production.

\begin{tabular}{|c|c|c|c|c|}
\hline $\begin{array}{l}\text { Acetyl-CoA Derived } \\
\text { Biochemical }\end{array}$ & $\begin{array}{c}\text { Acetyl-CoA Increasing Strategy } \\
\text { Applied }\end{array}$ & $\begin{array}{c}\text { Fold } \\
\text { Increased }\end{array}$ & $\begin{array}{c}\text { Titer } \\
\text { Achieved }\end{array}$ & Reference \\
\hline \multirow{3}{*}{ Isoamyl acetate } & $\begin{array}{c}\text { Increasing pyruvate } \\
\text { dehydrogenase activity; gene } \\
\text { deletion to reduce acetate } \\
\text { formation }\end{array}$ & 1.5 & $0.023 \mathrm{~g} / \mathrm{L}$ & [16] \\
\hline & $\begin{array}{l}\text { Gene deletion to reduce acetate } \\
\text { formation }\end{array}$ & 4.8 & $0.23 \mathrm{~g} / \mathrm{L}$ & {$[36]$} \\
\hline & $\begin{array}{c}\text { Gene deletion to reduce acetate } \\
\text { formation; increasing CoA } \\
\text { availability }\end{array}$ & 2.3 & $0.144 \mathrm{~g} / \mathrm{L}$ & [61] \\
\hline Isopropanol & Pyruvate dehydrogenase bypass & 4.4 & $3.8 \mathrm{~g} / \mathrm{L}$ & [68] \\
\hline 1,4-Butanediol & $\begin{array}{l}\text { Increasing pyruvate } \\
\text { dehydrogenase activity }\end{array}$ & 2.0 & $7.5 \mathrm{~g} / \mathrm{L}$ & {$[24]$} \\
\hline \multirow{2}{*}{ 1-Butanol } & $\begin{array}{l}\text { Increasing pyruvate } \\
\text { dehydrogenase activity }\end{array}$ & 1.6 & $4.3 \mathrm{~g} / \mathrm{L}$ & [23] \\
\hline & $\begin{array}{l}\text { Gene deletion to reduce acetate } \\
\text { formation }\end{array}$ & 10 & $30 \mathrm{~g} / \mathrm{L}$ & [40] \\
\hline \multirow[t]{2}{*}{ Poly-3-hydroxybutyrate } & $\begin{array}{l}\text { Increasing pyruvate flux; } \\
\text { increasing pyruvate } \\
\text { dehydrogenase activity }\end{array}$ & 2.7 & $5.5 \mathrm{~g} / \mathrm{L}$ & [26] \\
\hline & Threonine bypass & 2.9 & $5.97 \mathrm{~g} / \mathrm{L}$ & [77] \\
\hline N-Acetylglutamate & $\begin{array}{l}\text { Gene deletion to reduce acetate } \\
\text { formation; acetate assimilation }\end{array}$ & 2.0 & $17.8 \mathrm{~g} / \mathrm{L}$ & [31] \\
\hline 3-Hydroxypropionate & Acetate assimilation & 2.5 & $0.25 \mathrm{~g} / \mathrm{L}$ & [33] \\
\hline Citramalate & $\begin{array}{c}\text { Gene deletion to reduce acetate } \\
\text { formation; gene deletion to } \\
\text { disrupt TCA cycle }\end{array}$ & 1.2 & $19.8 \mathrm{~g} / \mathrm{L}$ & [53] \\
\hline Succinate & Increasing CoA availability & 1.3 & $2.7 \mathrm{~g} / \mathrm{L}$ & [62] \\
\hline \multirow[t]{2}{*}{ Fatty acid } & $\begin{array}{c}\text { Increasing pyruvate flux; } \\
\text { increasing pyruvate } \\
\text { dehydrogenase activity; gene } \\
\text { deletion to disrupt TCA cycle }\end{array}$ & 5.6 & $0.47 \mathrm{~g} / \mathrm{L}$ & [17] \\
\hline & Acetate assimilation & 2.2 & $0.68 \mathrm{~g} / \mathrm{L}$ & [30] \\
\hline Mevalonate & Pyruvate dehydrogenase bypass & 1.4 & $0.37 \mathrm{~g} / \mathrm{L}$ & [66] \\
\hline Isoprene & $\begin{array}{l}\text { Gene deletion to reduce acetate } \\
\text { formation }\end{array}$ & 2.0 & $1.8 \mathrm{~g} / \mathrm{L}$ & [43] \\
\hline
\end{tabular}

Author Contributions: E.I.L., J.T.K., and A.Y.C. wrote the manuscript. All authors read and approved of the final manuscript.

Funding: This work was funded by the Ministry of Science and Technology (MOST), Taiwan, R.O.C. through grant MOST 109-2636-B-009-002 under the Young Scholar Fellowship Program.

Conflicts of Interest: The authors declare that they have no competing interests.

\section{References}

1. de Kok, A.; Hengeveld, A.F.; Martin, A.; Westphal, A.H. The pyruvate dehydrogenase multi-enzyme complex from Gram-negative bacteria. Biochim. Et Biophys. Acta (Bba)-Protein Struct. Mol. Enzymol. 1998, 1385, 353-366. [CrossRef]

2. Shen, L.C.; Atkinson, D.E. Regulation of pyruvate dehydrogenase from Escherichia coli interactions of adenylate energy charge and other regulatory parameters. J. Biol. Chem. 1970, 245, 5974-5978.

3. Dietrich, J.; Henning, U. Regulation of pyruvate dehydrogenase complex synthesis in Escherichia coli K12: Identification of the inducing metabolite. Eur. J. Biochem. 1970, 14, 258-269. [CrossRef] 
4. Kumari, S.; Beatty, C.M.; Browning, D.F.; Busby, S.J.; Simel, E.J.; Hovel-Miner, G.; Wolfe, A.J. Regulation of acetyl coenzyme A synthetase in Escherichia coli. J. Bacteriol. 2000, 182, 4173-4179. [CrossRef] [PubMed]

5. Hennig, J.; Kern, G.; Neef, H.; Spinka, M.; Bisswanger, H.; Hübner, G. Molecular mechanism of regulation of the pyruvate dehydrogenase complex from E. coli. Biochemistry 1997, 36, 15772-15779. [CrossRef] [PubMed]

6. Broussard, T.C.; Price, A.E.; Laborde, S.M.; Waldrop, G.L. Complex formation and regulation of Escherichia coli acetyl-CoA carboxylase. Biochemistry 2013, 52, 3346-3357. [CrossRef] [PubMed]

7. Ravindran, S.; Radke, G.A.; Guest, J.R.; Roche, T.E. Lipoyl domain-based mechanism for the integrated feedback control of the pyruvate dehydrogenase complex by enhancement of pyruvate dehydrogenase kinase activity. J. Biol. Chem. 1996, 271, 653-662. [CrossRef]

8. Sawers, G.; Suppmann, B. Anaerobic induction of pyruvate formate-lyase gene expression is mediated by the ArcA and FNR proteins. J. Bacteriol. 1992, 174, 3474-3478. [CrossRef]

9. Holms, H. Flux analysis and control of the central metabolic pathways in Escherichia coli. Fems Microbiol. Rev. 1996, 19, 85-116. [CrossRef]

10. Kitamura, S.; Toya, Y.; Shimizu, H. (13)C-Metabolic Flux Analysis Reveals Effect of Phenol on Central Carbon Metabolism in Escherichia coli. Front. Microbiol. 2019, 10, 1010. [CrossRef]

11. Takamura, Y.; Nomura, G. Changes in the intracellular concentration of acetyl-CoA and malonyl-CoA in relation to the carbon and energy metabolism of Escherichia coli K12. Microbiology 1988, 134, 2249-2253. [CrossRef] [PubMed]

12. Chohnan, S.; Izawa, H.; Nishihara, H.; TAKAMURA, Y. Changes in size of intracellular pools of coenzyme A and its thioesters in Escherichia coli K-12 cells to various carbon sources and stresses. Biosci. Biotechnol. Biochem. 1998, 62, 1122-1128. [CrossRef] [PubMed]

13. Chohnan, S.; Furukawa, H.; Fujio, T.; Nishihara, H.; Takamura, Y. Changes in the size and composition of intracellular pools of nonesterified coenzyme A and coenzyme A thioesters in aerobic and facultatively anaerobic bacteria. Appl. Environ. Microbiol. 1997, 63, 553-560. [CrossRef]

14. De Graef, M.R.; Alexeeva, S.; Snoep, J.L.; de Mattos, M.J.T. The steady-state internal redox state (NADH/NAD) reflects the external redox state and is correlated with catabolic adaptation in Escherichia coli. J. Bacteriol. 1999, 181, 2351-2357. [CrossRef]

15. Hasona, A.; Kim, Y.; Healy, F.; Ingram, L.; Shanmugam, K. Pyruvate formate lyase and acetate kinase are essential for anaerobic growth of Escherichia coli on xylose. J. Bacteriol. 2004, 186, 7593-7600. [CrossRef]

16. Dittrich, C.R.; Vadali, R.V.; Bennett, G.N.; San, K.Y. Redistribution of metabolic fluxes in the central aerobic metabolic pathway of E. coli mutant strains with deletion of the ackA-pta and poxB pathways for the synthesis of isoamyl acetate. Biotechnol. Prog. 2005, 21, 627-631. [CrossRef]

17. Xu, P.; Ranganathan, S.; Fowler, Z.L.; Maranas, C.D.; Koffas, M.A. Genome-scale metabolic network modeling results in minimal interventions that cooperatively force carbon flux towards malonyl-CoA. Metab. Eng. 2011, 13, 578-587. [CrossRef]

18. Xu, P.; Gu, Q.; Wang, W.; Wong, L.; Bower, A.G.; Collins, C.H.; Koffas, M.A. Modular optimization of multi-gene pathways for fatty acids production in E. coli. Nat. Commun. 2013, 4, 1-8. [CrossRef]

19. Hirokawa, Y.; Kubo, T.; Soma, Y.; Saruta, F.; Hanai, T. Enhancement of acetyl-CoA flux for photosynthetic chemical production by pyruvate dehydrogenase complex overexpression in Synechococcus elongatus PCC 7942. Metab. Eng. 2020, 57, 23-30. [CrossRef]

20. Hansen, H.; Henning, U. Regulation of pyruvate dehydrogenase activity in Escherichia coli K12. Biochim. Et Biophys. Acta 1966, 122, 355-358. [CrossRef]

21. Kim, Y.; Ingram, L.; Shanmugam, K. Dihydrolipoamide dehydrogenase mutation alters the NADH sensitivity of pyruvate dehydrogenase complex of Escherichia coli K-12. J. Bacteriol. 2008, 190, 3851-3858. [CrossRef] [PubMed]

22. Wang, Q.; Ou, M.S.; Kim, Y.; Ingram, L.; Shanmugam, K. Metabolic flux control at the pyruvate node in an anaerobic Escherichia coli strain with an active pyruvate dehydrogenase. Appl. Environ. Microbiol. 2010, 76, 2107-2114. [CrossRef] [PubMed]

23. Saini, M.; Li, S.-Y.; Wang, Z.W.; Chiang, C.-J.; Chao, Y.-P. Systematic engineering of the central metabolism in Escherichia coli for effective production of n-butanol. Biotechnol. Biofuels 2016, 9, 69. [CrossRef] [PubMed]

24. Yim, H.; Haselbeck, R.; Niu, W.; Pujol-Baxley, C.; Burgard, A.; Boldt, J.; Khandurina, J.; Trawick, J.D.; Osterhout, R.E.; Stephen, R. Metabolic engineering of Escherichia coli for direct production of 1,4-butanediol. Nat. Chem. Biol. 2011, 7, 445. [CrossRef] 
25. Ranganathan, S.; Suthers, P.F.; Maranas, C.D. OptForce: An Optimization Procedure for Identifying All Genetic Manipulations Leading to Targeted Overproductions. PLoS Comput Biol 2010, 6, e1000744. [CrossRef]

26. Zhang, Y.; Lin, Z.; Liu, Q.; Li, Y.; Wang, Z.; Ma, H.; Chen, T.; Zhao, X. Engineering of Serine-Deamination pathway, Entner-Doudoroff pathway and pyruvate dehydrogenase complex to improve poly (3-hydroxybutyrate) production in Escherichia coli. Microb. Cell Factories 2014, 13, 172. [CrossRef]

27. Dittrich, C.R.; Bennett, G.N.; San, K.Y. Characterization of the acetate-producing pathways in Escherichia coli. Biotechnol. Prog. 2005, 21, 1062-1067. [CrossRef]

28. Fraenkel, D.; Neidhardt, F. Escherichia coli and Salmonella: Cellular and molecular biology; ASM Press: Washington DC, USA, 1996.

29. Lin, H.; Castro, N.M.; Bennett, G.N.; San, K.-Y. Acetyl-CoA synthetase overexpression in Escherichia coli demonstrates more efficient acetate assimilation and lower acetate accumulation: A potential tool in metabolic engineering. Appl. Microbiol. Biotechnol. 2006, 71, 870-874. [CrossRef]

30. Wu, J.; Zhang, X.; Xia, X.; Dong, M. A systematic optimization of medium chain fatty acid biosynthesis via the reverse beta-oxidation cycle in Escherichia coli. Metab. Eng. 2017, 41, 115-124. [CrossRef]

31. Zhang, S.; Yang, W.; Chen, H.; Liu, B.; Lin, B.; Tao, Y. Metabolic engineering for efficient supply of acetyl-CoA from different carbon sources in Escherichia coli. Microb. Cell Factories 2019, 18, 130. [CrossRef]

32. Chen, J.; Li, W.; Zhang, Z.-Z.; Tan, T.-W.; Li, Z.-J. Metabolic engineering of Escherichia coli for the synthesis of polyhydroxyalkanoates using acetate as a main carbon source. Microb. Cell Factories 2018, 17, 102. [CrossRef]

33. Lee, J.H.; Cha, S.; Kang, C.W.; Lee, G.M.; Lim, H.G.; Jung, G.Y. Efficient conversion of acetate to 3-hydroxypropionic acid by engineered Escherichia coli. Catalysts 2018, 8, 525. [CrossRef]

34. Yoo, S.M.; Na, D.; Lee, S.Y. Design and use of synthetic regulatory small RNAs to control gene expression in Escherichia coli. Nat. Protoc. 2013, 8, 1694-1707. [CrossRef]

35. Larson, M.H.; Gilbert, L.A.; Wang, X.W.; Lim, W.A.; Weissman, J.S.; Qi, L.S. CRISPR interference (CRISPRi) for sequence-specific control of gene expression. Nat. Protoc. 2013, 8, 2180-2196. [CrossRef]

36. Vadali, R.; Horton, C.; Rudolph, F.; Bennett, G.; San, K.-Y. Production of isoamyl acetate in ackA-pta and/or ldh mutants of Escherichia coli with overexpression of yeast ATF2. Appl. Microbiol. Biotechnol. 2004, 63, 698-704. [CrossRef]

37. van Wegen, R.J.; Lee, S.Y.; Middelberg, A.P. Metabolic and kinetic analysis of poly (3-hydroxybutyrate) production by recombinant Escherichia coli. Biotechnol. Bioeng. 2001, 74, 70-81. [CrossRef]

38. Ku, J.T.; Lan, E.I. A balanced ATP driving force module for enhancing photosynthetic biosynthesis of 3-hydroxybutyrate from $\mathrm{CO}_{2}$. Metab. Eng. 2018, 46, 35-42. [CrossRef]

39. Centeno-Leija, S.; Huerta-Beristain, G.; Giles-Gómez, M.; Bolivar, F.; Gosset, G.; Martinez, A. Improving poly-3-hydroxybutyrate production in Escherichia coli by combining the increase in the NADPH pool and acetyl-CoA availability. Antonie Van Leeuwenhoek 2014, 105, 687-696. [CrossRef]

40. Shen, C.R.; Lan, E.I.; Dekishima, Y.; Baez, A.; Cho, K.M.; Liao, J.C. Driving forces enable high-titer anaerobic 1-butanol synthesis in Escherichia coli. Appl. Environ. Microbiol. 2011, 77, 2905-2915. [CrossRef]

41. Ohtake, T.; Pontrelli, S.; Laviña, W.A.; Liao, J.C.; Putri, S.P.; Fukusaki, E. Metabolomics-driven approach to solving a CoA imbalance for improved 1-butanol production in Escherichia coli. Metab. Eng. 2017, 41, 135-143. [CrossRef]

42. Lin, F.; Chen, Y.; Levine, R.; Lee, K.; Yuan, Y.; Lin, X.N. Improving fatty acid availability for bio-hydrocarbon production in Escherichia coli by metabolic engineering. PLoS ONE 2013, 8, e78595. [CrossRef]

43. Kim, J.-H.; Wang, C.; Jang, H.-J.; Cha, M.-S.; Park, J.-E.; Jo, S.-Y.; Choi, E.-S.; Kim, S.-W. Isoprene production by Escherichia coli through the exogenous mevalonate pathway with reduced formation of fermentation byproducts. Microb. Cell Factories 2016, 15, 214. [CrossRef]

44. Martin, C.H.; Dhamankar, H.; Tseng, H.-C.; Sheppard, M.J.; Reisch, C.R.; Prather, K.L. A platform pathway for production of 3-hydroxyacids provides a biosynthetic route to 3-hydroxy- $\gamma$-butyrolactone. Nat. Commun. 2013, 4, 1414. [CrossRef]

45. Zhu, H.; Gonzalez, R.; Bobik, T.A. Coproduction of acetaldehyde and hydrogen during glucose fermentation by Escherichia coli. Appl. Environ. Microbiol. 2011, 77, 6441-6450. [CrossRef] 
46. Vuoristo, K.S.; Mars, A.E.; Sangra, J.V.; Springer, J.; Eggink, G.; Sanders, J.P.; Weusthuis, R.A. Metabolic engineering of itaconate production in Escherichia coli. Appl. Microbiol. Biotechnol. 2015, 99, 221-228. [CrossRef]

47. Miyake, M.; Schnackenberg, J.; Kurane, R.; Asada, Y. Phosphotransacetylase as a key factor in biological production of polyhydroxybutyrate. Appl. Biochem. Biotechnol. 2000, 84, 1039-1044. [CrossRef]

48. Jian, J.; Zhang, S.-Q.; Shi, Z.-Y.; Wang, W.; Chen, G.-Q.; Wu, Q. Production of polyhydroxyalkanoates by Escherichia coli mutants with defected mixed acid fermentation pathways. Appl. Microbiol. Biotechnol. 2010, 87, 2247-2256. [CrossRef]

49. Ku, J.T.; Simanjuntak, W.; Lan, E.I. Renewable synthesis of n-butyraldehyde from glucose by engineered Escherichia coli. Biotechnol. Biofuels 2017, 10, 291. [CrossRef]

50. Srirangan, K.; Liu, X.; Akawi, L.; Bruder, M.; Moo-Young, M.; Chou, C.P. Engineering Escherichia coli for microbial production of butanone. Appl. Environ. Microbiol. 2016, 82, 2574-2584. [CrossRef]

51. Wang, J.; Niyompanich, S.; Tai, Y.-S.; Wang, J.; Bai, W.; Mahida, P.; Gao, T.; Zhang, K. Engineering of a highly efficient Escherichia coli strain for mevalonate fermentation through chromosomal integration. Appl. Environ. Microbiol. 2016, 82, 7176-7184. [CrossRef]

52. Lan, E.I.; Wei, C.T. Metabolic engineering of cyanobacteria for the photosynthetic production of succinate. Metab. Eng. 2016, 38, 483-493. [CrossRef]

53. Parimi, N.S.; Durie, I.A.; Wu, X.; Niyas, A.M.; Eiteman, M.A. Eliminating acetate formation improves citramalate production by metabolically engineered Escherichia coli. Microb. Cell Factories 2017, 16, 114. [CrossRef]

54. Lan, E.I.; Ro, S.Y.; Liao, J.C. Oxygen-tolerant coenzyme A-acylating aldehyde dehydrogenase facilitates efficient photosynthetic n-butanol biosynthesis in cyanobacteria. Energy Environ. Sci. 2013, 6, 2672-2681. [CrossRef]

55. Vallari, D.; Jackowski, S. Biosynthesis and degradation both contribute to the regulation of coenzyme A content in Escherichia coli. J. Bacteriol. 1988, 170, 3961-3966. [CrossRef]

56. Vadali, R.V.; Bennett, G.N.; San, K.-Y. Cofactor engineering of intracellular CoA/acetyl-CoA and its effect on metabolic flux redistribution in Escherichia coli. Metab. Eng. 2003, 6, 133-139. [CrossRef]

57. Jackowski, S.; Rock, C. Regulation of coenzyme A biosynthesis. J. Bacteriol. 1981, 148, 926-932. [CrossRef]

58. Rock, C.O.; Calder, R.B.; Karim, M.A.; Jackowski, S. Pantothenate kinase regulation of the intracellular concentration of coenzyme A. J. Biol. Chem. 2000, 275, 1377-1383. [CrossRef]

59. Song, W.-J.; Jackowski, S. Kinetics and regulation of pantothenate kinase from Escherichia coli. J. Biol. Chem. 1994, 269, 27051-27058.

60. Vallari, D.; Jackowski, S.; Rock, C. Regulation of pantothenate kinase by coenzyme A and its thioesters. J. Biol. Chem. 1987, 262, 2468-2471.

61. Vadali, R.V.; Bennett, G.N.; San, K.-Y. Applicability of CoA/acetyl-CoA manipulation system to enhance isoamyl acetate production in Escherichia coli. Metab. Eng. 2004, 6, 294-299. [CrossRef]

62. Lin, H.; Vadali, R.V.; Bennett, G.N.; San, K.Y. Increasing the acetyl-CoA pool in the presence of overexpressed phosphoenolpyruvate carboxylase or pyruvate carboxylase enhances succinate production in Escherichia coli. Biotechnol. Prog. 2004, 20, 1599-1604. [CrossRef] [PubMed]

63. Dong, L.-Y.; Masuda, T.; Kawamura, T.; Hata, S.; Izui, K. Cloning, expression, and characterization of a root-form phosphoenolpyruvate carboxylase from Zea mays: Comparison with the C4-form enzyme. Plant Cell Physiol. 1998, 39, 865-873. [CrossRef] [PubMed]

64. Chen, L.-m.; Omiya, T.; Hata, S.; Izui, K. Molecular characterization of a phosphoenolpyruvate carboxylase from a thermophilic cyanobacterium, Synechococcus vulcanus with unusual allosteric properties. Plant Cell Physiol. 2002, 43, 159-169. [CrossRef] [PubMed]

65. Ogata, Y.; Chohnan, S. Prokaryotic type III pantothenate kinase enhances coenzyme A biosynthesis in Escherichia coli. J. Gen. Appl. Microbiol. 2015, 61, 266-269. [CrossRef] [PubMed]

66. Shiba, Y.; Paradise, E.M.; Kirby, J.; Ro, D.-K.; Keasling, J.D. Engineering of the pyruvate dehydrogenase bypass in Saccharomyces cerevisiae for high-level production of isoprenoids. Metab. Eng. 2007, 9, 160-168. [CrossRef] [PubMed]

67. Liu, W.; Zhang, B.; Jiang, R. Improving acetyl-CoA biosynthesis in Saccharomyces cerevisiae via the overexpression of pantothenate kinase and PDH bypass. Biotechnol. Biofuels 2017, 10, 41. [CrossRef] 
68. Soma, Y.; Yamaji, T.; Matsuda, F.; Hanai, T. Synthetic metabolic bypass for a metabolic toggle switch enhances acetyl-CoA supply for isopropanol production by Escherichia coli. J. Biosci. Bioeng. 2017, 123, 625-633. [CrossRef]

69. Lai, M.J.; Lan, E.I. Photoautotrophic synthesis of butyrate by metabolically engineered cyanobacteria. Biotechnol. Bioeng. 2019, 116, 893-903. [CrossRef]

70. Lan, E.I.; Liao, J.C. ATP drives direct photosynthetic production of 1-butanol in cyanobacteria. Proc. Natl. Acad. Sci. USA 2012, 109, 6018-6023. [CrossRef]

71. Lee, H.J.; Son, J.; Sim, S.J.; Woo, H.M. Metabolic rewiring of synthetic pyruvate dehydrogenase bypasses for acetone production in cyanobacteria. Plant Biotechnol. J. 2020. [CrossRef]

72. Bogorad, I.W.; Lin, T.-S.; Liao, J.C. Synthetic non-oxidative glycolysis enables complete carbon conservation. Nature 2013, 502, 693-697. [CrossRef] [PubMed]

73. Henard, C.A.; Freed, E.F.; Guarnieri, M.T. Phosphoketolase pathway engineering for carbon-efficient biocatalysis. Curr. Opin. Biotechnol. 2015, 36, 183-188. [CrossRef] [PubMed]

74. Lin, P.P.; Jaeger, A.J.; Wu, T.-Y.; Xu, S.C.; Lee, A.S.; Gao, F.; Chen, P.-W.; Liao, J.C. Construction and evolution of an Escherichia coli strain relying on nonoxidative glycolysis for sugar catabolism. Proc. Natl. Acad. Sci. USA 2018, 115, 3538-3546. [CrossRef]

75. Mainguet, S.E.; Gronenberg, L.S.; Wong, S.S.; Liao, J.C. A reverse glyoxylate shunt to build a non-native route from C4 to C2 in Escherichia coli. Metab. Eng. 2013, 19, 116-127. [CrossRef] [PubMed]

76. Yu, H.; Li, X.; Duchoud, F.; Chuang, D.S.; Liao, J.C. Augmenting the Calvin-Benson-Bassham cycle by a synthetic malyl-CoA-glycerate carbon fixation pathway. Nat. Commun. 2018, 9, 2008. [CrossRef] [PubMed]

77. Lin, Z.; Zhang, Y.; Yuan, Q.; Liu, Q.; Li, Y.; Wang, Z.; Ma, H.; Chen, T.; Zhao, X. Metabolic engineering of Escherichia coli for poly (3-hydroxybutyrate) production via threonine bypass. Microb. Cell Factories 2015, 14, 185. [CrossRef]

78. Wang, J.; Ma, W.; Fang, Y.; Yang, J.; Zhan, J.; Chen, S.; Wang, X. Increasing 1-threonine production in Escherichia coli by overexpressing the gene cluster phaCAB. J. Ind. Microbiol. Biotechnol. 2019, 46, 1557-1568. [CrossRef]

79. Rodriguez, S.; Denby, C.M.; Van Vu, T.; Baidoo, E.E.; Wang, G.; Keasling, J.D. ATP citrate lyase mediated cytosolic acetyl-CoA biosynthesis increases mevalonate production in Saccharomyces cerevisiae. Microb. Cell Factories 2016, 15, 48. [CrossRef]

80. Kozak, B.U.; van Rossum, H.M.; Luttik, M.A.; Akeroyd, M.; Benjamin, K.R.; Wu, L.; de Vries, S.; Daran, J.-M.; Pronk, J.T.; van Maris, A.J. Engineering acetyl coenzyme A supply: Functional expression of a bacterial pyruvate dehydrogenase complex in the cytosol of Saccharomyces cerevisiae. MBio 2014, 5, e01696-01614. [CrossRef]

(C) 2020 by the authors. Licensee MDPI, Basel, Switzerland. This article is an open access article distributed under the terms and conditions of the Creative Commons Attribution (CC BY) license (http://creativecommons.org/licenses/by/4.0/). 